\title{
The Effects of Aging on the Femoral Bone Mass, Bone Stiffness and Maximum Resistance Strength - Assessed in a Rat Model
}

\author{
Sheila Martins Puelker, ${ }^{1,2}$ Sonia Regina Ribeiro de Castro, ${ }^{1,2}$ Romeu Rodrigues de Souza, ${ }^{3}$ Laura Beatriz Mesiano Maifrino, ${ }^{1}$ \\ Maria do Carmo Sitta ${ }^{4}$ \\ ${ }^{1}$ Programa de Pós-graduação (Stricto Sensu), em Ciências do Envelhecimento, Universidade São Judas Tadeu, São Paulo, SP, Brasil \\ ${ }^{2}$ Estética e Cosmetologia, Senac, São Paulo, SP, Brasil \\ ${ }^{3}$ Departamento de Anatomia, Universidade de São Paulo, São Paulo, SP, Brasil \\ ${ }^{4}$ Departamento de Geriatria, Faculdade de Medicina, Universidade de São Paulo, São Paulo, SP, Brasil
}

Disclose and conflicts of interest: none to be declared by all authors

\begin{abstract}
Introduction: previous studies of variation in bone dimensions and biomechanical characteristics with age have involved comparison of young and adult rats, but no data on age-related changes are available. Such data are important for studies of the response of bone to experimental stimuli in aged rats, to distinguish the response to the stimuli from accompanying age-related changes. The present study evaluates the bone mass, dimensions and biomechanical parameters of the femur in young, middle-aged, and aged rats. Thirty-six Wistar male rats were studied: 12 young animals, (3-month-old), 12 middle-aged animals (12-month-old) and 12 aged rats (18-month-old). The right femurs were subjected sequentially to morphometric study (bone weight, cortical thickness) and biomechanical tests (maximum resistance strength and bone stiffness). The statistical differences between groups of animals were tested using the nonparametric Mann-Whitney test $(p<0.05)$. The body weight increased from $274 \mathrm{~g}$ to $412.80 \mathrm{~g}$ and to $390 \mathrm{~g}$ in the groups; the bone weight increased from $0.596 \mathrm{~g}$ to $0.823 \mathrm{~g}$ and to $0.809 \mathrm{~g}$ in the groups; the cortical thickness increased from $380.20 \mu \mathrm{m}$ to $477.5 \mu \mathrm{m}$ and to $485.80 \mu \mathrm{m}$; the maximum resistance strength increased from $72.59 \mathrm{~N}$ to $131.5 \mathrm{~N}$ and to $132.4 \mathrm{~N}$ and the bone stiffness increased from $79.99 \mathrm{kN} / \mathrm{m}$ to $189.0 \mathrm{kN} / \mathrm{m}$ to $161.60 \mathrm{kN} / \mathrm{m}$. The differences between the 3-month-old and the two other groups were statistically significant $(p<0.05)$. The body weight increased $50 \%$ from 3 to 12 months and $42.3 \%$ from 3 to 18 months; the cortical thickness increased $25.6 \%$ from 3 to 12 months and $21.7 \%$ from 3 to 18 months; the maximum resistance strength increased $81.1 \%$ from 3 to 12 months and $82.31 \%$ from 3 to 18 months; the bone stiffness increased $136 \%$ from 3 to 12 months and $102.02 \%$ from 3 to 18 months. In conclusion, for the femoral bone of the Wistar rat, the cortical thickness, the maximum resistance strength and the bone stiffness increased from 3 to 12 mo, but not from 12- to 18- mo-old.
\end{abstract}

Keywords: Bone; Growing; Aging; Morphometry; Biomechanical tests.

\section{Introduction}

Bone tissue is a critical component of the function of the musculoskeletal system. The biomechanical characteristics of long bones, such as the bone density, maximum resistance force, and bone stiffness differ between individuals, within the same individuals between bones, and within the same bone as a function of load distribution..$^{1-6}$ These characteristics are also dependent upon age and developmental stage., ${ }^{4,7}$

Although several studies have been performed to examine the effects of growing and aging on bone biomechanical properties, these studies have involved a comparison of young and adult individuals., However, little data on long-term age-related change are available. ${ }^{10,11}$ Such data are important for studies of the response of the bone experimental stimuli in aged rats, to distinguish the response to the stimuli from accompanying age-related changes. ${ }^{12}$

Morphometry is a method of quantitative morphology that allows accurate determination of changes in different tissues with increasing age ${ }^{7,13-18}$. The purpose of the present work was to investigate the bone density, maximum resistance force, and bone stiffness of the rat femur, as a function of growing and aging.

\section{Material and Methods}

The University Ethics Committee approved the handling of the rats in adherence to the International Guiding Principles for Biomedical Research involving Animals.

The femoral bones were obtained from 30 Wistar male rats, that were randomly assigned to the 3-mo-old $(\mathrm{n}=10), 12$-mo-old group $(\mathrm{n}=10)$ or the 18-mo-old group 
$(n=10)$. During the experiment, food and water were provided ad libitum to all rats. The rats were weighed at the time of sacrifice. The rats were sacrificed with an overdose of sodium pentobarbital intraperitoneally. At death, the right hind limb was dissected from the body. After removal of all muscles and other tissues, the femur was then weighed and prepared for analysis.

\section{Measurement of cortical thickness}

Measurements of the cortical thickness were taken at the distal extremity of the femur, which was cut longitudinally with a scalpel to expose the cortical bone. All bones were fixed in 100\% ethanol, decalcified, embedded in methacrylate, and sectioned into histological sections with a tungsten knife (Junk, Carl Zeiss, Germany). The sections were stained with $0.1 \%$ toluidine blue ( $\mathrm{pH}$ 6.4) (Fig. 1). A microscope (NIKON, LABOPHOT-2A) was used with a $4 \times 10 \times 1.25$ magnification eyepiece, with a millimeter-scale reticle, calibrated using a Vernier scale.

The cortical thickness of the histological sections was measured at 4 equidistant sites of 2 slides selected from the 4 prepared slides. The final value was the average of these values expressed in micrometers $(\mu \mathrm{m})$. The method and regulation of the equipment were defined in preliminary tests using a pilot study under the same conditions. All tests were documented by a 790 BBC GOERZ METRAWATT SERVOGOR graphic recorder to obtain the "load-deformation" curve of each test.

\section{Biomechanical tests}

Measurements were taken on a KRATOS universal biomechanical testing machine, model K5002. A threepoint bending test device was used, where a $7 \mathrm{~mm}^{-}$ diameter $\times 30 \mathrm{~mm}$-wide cylindrical cutter is attached to the crosshead of the testing machine, with a load cell of $100 \mathrm{kgf}$, to a scale of 2 , therefore with $25 \mathrm{kgf}$. Two $4 \mathrm{~mm}$-diameter metal cylinders were used to hold the bones in position, adjusted with a bench vise mounted to the base of the machine with a $25 \mathrm{~mm}$-distance between the supports, with the cutter centered.

The bone was positioned and centered on the cylindrical supports by attaching the proximal portion of the femur between the neck and the lesser trochanter. It was observed that, in that position, the bone remained stationary during the test, with no displacements that could compromise the test.

The cutter attached to the load cell was directed perpendicular to the axis of the femoral diaphysis and moved at a constant speed of $5 \mathrm{~mm} / \mathrm{min}$ until bone fracture occurred.

The maximum resistance strength and deformation values were determined for each curve. The following parameters were considered:

- Maximum resistance strength in newtons (N) represents the maximum load applied to the femur until a fracture occurs; it was used to calculate the bone stiffness;

- Deformation in millimeters ( $\mathrm{mm}$ ) - is a measure of the deformation (flexural strain) suffered by the bone at the maximum load limit;

- Bone stiffness in kilonewtons/millimeter $(\mathrm{kN} / \mathrm{mm})$ - is calculated by dividing Force $(\mathrm{kN})$ by deformation $(\mathrm{mm})$. This parameter represents the deformability of the material when the load is applied and, therefore, represents the stiffness of the material.

\section{Statistical Analysis}

Statistical significance was evaluated by ANOVA and post Mann-Whitney's test. Statistical significance was set at $P$ values less than 0.05 .

\section{Results}

Looking at the results obtained for 3-mo-old, 12-moold and 18-mo-old animals, we found value differences between the groups of rats. (Table 1 and Figure 1).

Table 1 - Body and bone weight, cortical thickness and biomechanical parameters of the femur in 3-moold, 12-mo-old and 18-mo-old groups of rats.
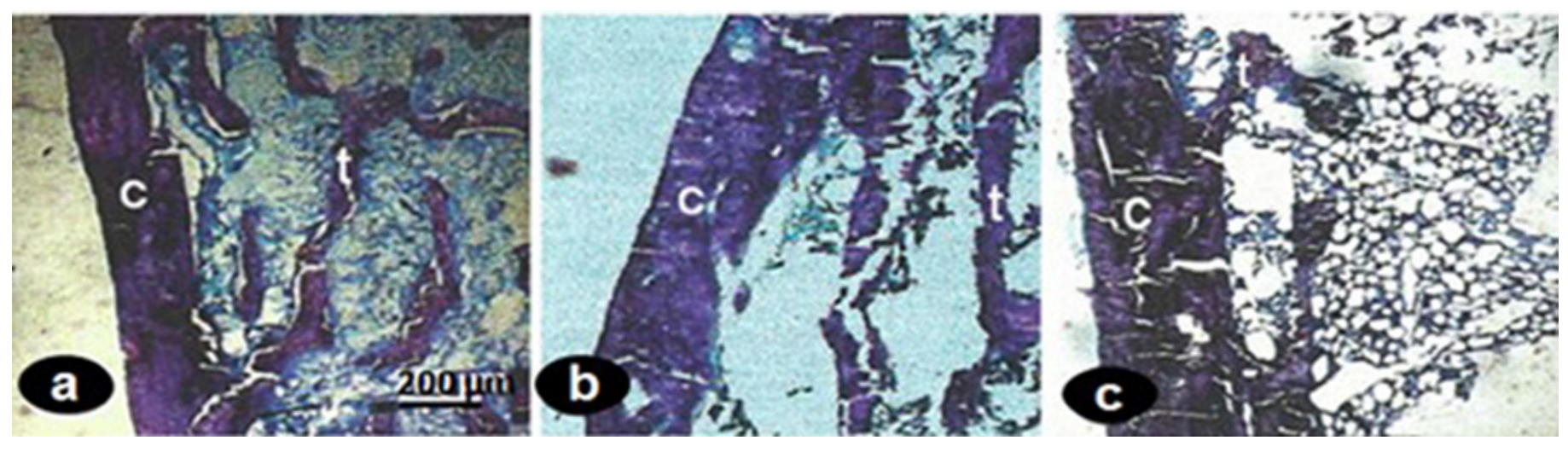

Figure 1. Photomicrographs of histological sections obtained from the distal extremity of the femur for measurement of the cortical thickness (C). a- 3-mo-old group; b-12-mo-old group; c- 18-mo old group. Toluidine blue staining. t-trabeculae of spongy bone 
Table 1. Body and bone weight, cortical thickness and biomechanical parameters of the femur in 3-mo-old, 12-mo-old and 18-mo-old groups of rats.

\begin{tabular}{l|c|c|c}
\hline \multicolumn{1}{c|}{ Pameters } & 3-mo-old & 12-mo-old & 18-mo-old \\
\hline Body weight $(\mathrm{g})$ & $274.50 \pm 5.88$ & $412.80 \pm 14.0^{*}$ & $30.70 \pm 13.48^{*}$ \\
\hline Cortical Thickness $(\mu \mathrm{m})$ & $380.20 \pm 9.99$ & $477.5 \pm 20.5^{*}$ & $485.80 \pm 17.49^{*}$ \\
\hline Maximum Strength $(\mathrm{N})$ & $72.59 \pm 3.57$ & $131.5 \pm 5.5^{*}$ & $132.40 \pm 7.17^{*}$ \\
\hline Stiffness $(\mathrm{kN} / \mathrm{m})$ & $79.99 \pm 4.44$ & $189.0 \pm 12.5^{*}$ & $161.60 \pm 8.02^{*}$ \\
\hline
\end{tabular}

$M \pm M S M * p<0.05)$ vs. 3-mo-old rats

\section{Discussion}

The objective of this study was to observe the effects of aging on the femoral cortical thickness, maximum strength and stiffness of the femur of rats.

Knowledge of the bone aging process is important to understand common pathological processes affecting the elderly. In the present study, it should be considered that no immobilization model was used to study bone tissue aging, in accordance with Paz et al..$^{19}$ The aged rat groups maintained normal spontaneous movement inside the cage and, and therefore, serves as a model of normal bone aging for laboratory rats under standard conditions.

The body weight of the animals was similar at the age of 3 months. It can be inferred that the animals formed a homogeneous group for the comparisons and measurements made. Animals in the 12-mo-old and 18-mo-old groups had a significant increase in body weight compared to the 3 -mo-old animals. In the first 7 months of life of the animals a constant weight gain occurs initially, positively accelerated but then slows down gradually tending to a relative asymptotic stability.

This is the known trend in ponderal evolution of rats. This evolution is due to the increased volume of tissues and organs that occurs during growth and aging. ${ }^{20}$

The bone weight increased significantly from 0.596 $\mathrm{g}$ to $0.823 \mathrm{~g}$ and to $0.809 \mathrm{~g}$ in the three groups. For the cortical thickness, the 12-mo-group and 18-monthold group had values significantly higher compared to 3-month-old group and the difference was significant.
In the present paper, biomechanical properties were assessed using force, which is a parameter that measures bone strength, and using stiffness, which measures the deformation of the material when maximum force is applied. The 12-mo-old and 18-month-old groups showed a significant increase in maximum strength in relation to the 3-month-old group. Maximum strength is one of the most widely used parameters for a qualitative study of bone and is present in most studies on experimental osteoporosis. Stiffness in the aged groups showed a significant difference in relation to the initial 3-month-old group. As for aging, according to Kiebzak et al $^{10}$, a progressive and slow increase in bone length and width is expected, but not in the cortical area, which makes the rat a good model for studying age-related osteopenia. In this research, the highest values for diameter were at the age of 12 and 18 months in force and stiffness, and the highest value for cortical thickness was also at the age of 12 and 18 months.

Collaborating with the present findings, in the 3-month-old group, the bone mineral density (BMD) was significantly lower in relation to the aged overall, force, and stiffness, and we found that, as for normal aging, the highest values for both the densitometric and biomechanical values were at the age of 12 and 18 months.

In summary, for the femoral bone of the Wistar rat, the cortical thickness, the maximum resistance strength and the bone stiffness increased from 3 to 12 mo, but not from 12- to 18- mo-old.

\section{References}

1. Bosher, S. K., \& Hallpike, C. S. Observations on the histological features, development and pathogenesis of the inner ear degeneration of the deaf white cat. Proceedings of the Royal Society B: Biological Sciences, 1965; 162(987): 147-170.

2. Mosekilde L., Danielsen C.C., Sogaard C.H., Thorling E. The Effect of long-term exercise on vertebral and femoral bone mass, dimensions, and strength - assessed in a rat model Bone 1994;15:293-301.

3. Peng Z, Zuukkanen J, Väänänen H 1994 Exercise can provide protection against bone loss and prevent the decrease in mechanical strength of femoral neck in ovariectomized rats. J Bone Miner Res 1994; 9:1559-1564.

4. Søgaard C.H., Danielsen C.C., Thorling E.B., Mosekilde L. Longterm exercise of young and adult female rats: Effect on femoral neck biomechanical competence and bone structure. J Bone Min
Res. 1965; 9:409-416.

5. Smith E.L,Gilligan C. Dose-response relationship between physical loading and mechanical competence of boné. Bone. 1996; 18(1 Suppl):455-505.

6. Kennedy O. D., Brennan O., Rackard S.M., O'Brien F.J., Taylor D., Lee T.C. Variation of trabecular microarchitectural parameters in cranial, caudal and mid-vertebral regions of the ovine L3 vertebra. J Anat. 2009; 214(5): 729-735.

7. Nagai T, Mistretta CM, Bradley RM. Developmental decrease in size of peripheral receptive fields of single chorda tympani nerve fibers and relation to increasing $\mathrm{NaCl}$ taste sensitivity-Journal of Neuroscience, 1988; 8 (1) 64-72

8. Pastoureau P, Chomel A., Bonnet J. Specific evaluation of localized bone mass and bone loss in the rat using dual energy 
X-ray absorptiometry subregional analysis. Osteoporos. Int., 1995; 5(3):143-149.

9. Stenderup K., Justesen J., Clausen C., Kassem M. Aging is associated with decreased maximal life span and accelerated senescense of bone marrow stromal cells. Bone 2003, 33(6):919-26.

10. Kiebzak GM et al. Conteúdo de minerais ósseos no fêmur do rato senor: uma avaliação usando a absorção de fotões única. J Bone Miner Res 1988, 3:311-317.

11. Boskey, A. L. \& Coleman, R. (2010). Aging and Bone. J Dent Res. 2010 Dec;89(12):1333-48

12. Ferrucci, L., Baroni, M., Ranchelli, A., Lauretani, F., Maggio, M., Mecocci, P., \& Ruggiero, C. Interaction between bone and muscle in older persons with mobility limitations. Current Pharmaceutical Design. 2014, 20(19), 3178-3197.

13. Kajstura J., Cheng W., Reiss $\mathrm{K}$ et al. Apoptotic and necrotic myocyte cell deaths are independent contributing variables of infarct size in rats. Lab Invest. 1996, 74(1): 86-107.

14. Mayhew T.M., Olsen D.R. Magnetic resonance imaging (MRI) and model-free stimates of brain volume determined using the Cavalieri principle. Journal of Anatomy, 1991, 178:133-134.

15. Aguila, M. B.; Mandarim-de-Lacerda, C. A and Apfel, M. I. R.
Estereologia do miocárdio de ratos jovens e idosos. Arquivos Brasileiros de Cardiologia 1998, 70 (2):105-109.

16. De Souza R.R, Sitta M.C., Santarem Sobrinho J.M., Jacob Filho W. Long term running exercise vs long term strength exercise on fermoral bone mass assessed in a rat model - JEPonline, 2013, 2:9298

17. Brianezi, L, Marques M. R., Cardoso C. G., Miranda M. L. J., Fonseca F.L.A., Maifrino L.B.M. Effects of physical training on the myocardium of female LDL knockout ovariectomized mice. Revista Brasileira de Medicina do Esporte, 2017, 23(6): 441-445.

18 Maifrino L. B. M. , Lima N. E. A. , Marques M. R. et al, Evaluation of Collagen Fibers, MMP2, MMP9, 8-OHdG and Apoptosis in the Aorta of Ovariectomized LDL Knockout Mice Submitted to Aerobic ExerciseArq Bras Cardiol. 2019, 112(2): 180-188.

19. Paz S., Spindler A., Berman A.C. Muscular Strength and boné mineral density in haemodialysis patients - Nephrol Dial Transplant, 1977, 12 (1) 128-132.

20. Curi R., Hell N.S.,Bazotte R.B.,Timo-Laria C. Metabolic performance of free fed rats subjectedto prolonged fast as comparedto tjhe metabolic pattern in rats under long term food restriction - Physiol Behav.1994, 4 525-31
Received: April 11, 2019

Accepted: October 15, 2019
Corresponding author

Romeu Rodrigues de Souza

souzarrd@uol.com.br 